\title{
Declining malformation rates with changed antiepileptic drug prescribing
}

An observational study

\author{
Torbjörn Tomson, MD, * Dina Battino, MD, * Erminio Bonizzoni, PhD, John Craig, MD, Dick Lindhout, MD, \\ Emilio Perucca, MD, Anne Sabers, MD, Sanjeev V. Thomas, MD, and Frank Vajda, MD, \\ for The EURAP Study Group
}

Neurology ${ }^{\circledR}$ 2019;93:e1-e10. doi:10.1212/WNL.0000000000008001

\section{Abstract}

\section{Objective}

Changes in prescribing patterns of antiepileptic drugs (AEDs) in pregnant women with epilepsy would be expected to affect the risk of major congenital malformations (MCMs). To test this hypothesis, we analyzed data from an international pregnancy registry (EURAP).

\section{Methods}

EURAP is an observational prospective cohort study designed to determine the risk of MCMs after prenatal exposure to AEDs. The Cochrane-Armitage linear trend analysis was used to assess changes in AED treatment, prevalence of MCMs, and occurrence of generalized tonicclonic seizures (GTCs) over 3 time periods: 2000-2005 ( $n=4,760), 2006-2009(n=3,599)$, and 2010-2013 $(\mathrm{n}=2,949)$.

\section{Results}

There were pronounced changes in the use of specific AEDs over time, with a decrease in the use of valproic acid and carbamazepine and an increase in the use of lamotrigine and levetiracetam. The prevalence of MCMs with monotherapy exposure decreased from $6.0 \%$ in 2000-2005 to 4.4\% in 2010-2013. The change over time in MCM frequency after monotherapy exposure showed a significant linear trend in the crude analysis $(p=0.0087)$, which was no longer present after adjustment for changes in AED treatment $(p=0.9923)$. There was no indication of an increase over time in occurrence of GTCs during pregnancy.

\section{Conclusions}

There have been major changes in AED prescription patterns over the years covered by the study. In parallel, we observed a significant $27 \%$ decrease in the prevalence of MCMs. The results of adjusting the trend analysis for MCMs for changes in AED treatment suggest that changes in prescription patterns played a major role in the reduction of teratogenic events.

\author{
Correspondence \\ Dr. Tomson \\ torbjorn.tomson@sll.se
}

\section{RELATED ARTICLE}

\section{Editorial}

Reducing birth defects in women with epilepsy: Research leading to results Page 375

\footnotetext{
*These authors contributed equally to this work.

From the Department of Clinical Neuroscience (T.T.), Karolinska Institutet; Department of Neurology (T.T.), Karolinska University Hospital, Stockholm, Sweden; Epilepsy Center, Department of Neurophysiology and Experimental Epileptology (D.B.), Fondazione IRCCS Istituto Neurologico Carlo Besta; Department of Clinical Science and Community (E.B.), Section of Medical Statistics, Biometry and Epidemiology "G.A. Maccacaro," Faculty of Medicine and Surgery, University of Milan, Italy; Belfast Health and Social Care Trust (I.C.), Belfast, UK; Department of Genetics (D.L.), University Medical Center Utrecht; Stichting Epilepsie Instellingen Nederland (SEIN) (D.L.), Heemstede, the Netherlands; Department of Internal Medicine and Therapeutics (E.P.), University of Pavia; Clinical Trial Center (E.P.), IRCCS Mondino Foundation, Pavia, Italy; The Epilepsy Clinic, Department of Neurology (A.S.), Rigshospitalet-Blegdamsvej, University State Hospital, Copenhagen, Denmark; Department of Neurology (S.V.T.), Sree Chitra Tirunal Institute of Medical Sciences and Technology, Trivandrum, Kerala State, India; Departments of Medicine and Neurology (F.V.), University of Melbourne and Monash University; and Royal Melbourne Hospital (F.V.), Australia. 


\section{Glossary}

AED = antiepileptic drug; EMA = European Medicines Agency; GTC = generalized tonic-clonic; $\mathbf{M C M}=$ major congenital malformation.

Since the first report of an association between fetal exposure to antiepileptic drugs (AEDs) and an increased risk of major congenital malformations (MCMs), ${ }^{1}$ there have been major advances in characterizing the teratogenicity of individual AEDs. During the last decade, data from large prospective AEDs and pregnancy registries ${ }^{2-7}$ and other prospective observational cohort studies ${ }^{8-10}$ have enabled comparisons of risks associated with different treatments. ${ }^{2-7}$ These data have consistently shown that, in comparison with many other AEDs, valproic acid is associated with a higher prevalence of MCMs as well as an increased risk for impaired cognitive and behavioral development of the exposed offspring. ${ }^{2-11}$ The risks associated with valproic acid appear to be dose-dependent. ${ }^{2-10,12}$ These findings provided physicians with tools for more rational, evidence-based treatment decisions and prompted the US Food and Drug Administration ${ }^{13}$ and the European Medicines Agency (EMA) ${ }^{14}$ to tighten the restrictions on the use of valproic acid in women of childbearing potential. Recent reports indicate that prescription patterns for women with epilepsy have changed over time and that the use of valproic acid has been declining in women ${ }^{15,16}$ including women during pregnancy. ${ }^{17-19}$ However, information on possible changes in pregnancy outcomes in parallel with changes in AED utilization are scarce. ${ }^{17,19,20}$

In this study, we used data from the EURAP registry's longitudinal prospective cohort to analyze changes in AED treatment and pregnancy outcomes over the 14-year period (2000-2013) preceding EMA's introduction of further restrictions on valproic acid use.

\section{Methods}

\section{Eligibility criteria and study procedures}

The current analysis assessed time trends in the use of different AED treatments and in teratogenic outcomes based on data from the EURAP international registry, whose primary aim is to compare the risk of MCMs at 1 year after birth in offspring exposed to AED treatments prenatally. The EURAP methodology has been described in detail before. $^{6}$

Eligible for prospective assessment in EURAP are pregnancies exposed to AEDs at conception, enrolled within gestation week 16 (based on the date of the last menstrual period) and before fetal outcome is known. Information on demographics, type of epilepsy, seizure frequency, comorbidities, family history of MCMs, drug treatment, and other risk factors is obtained in early pregnancy.
Follow-up data are obtained after each trimester, at birth, and 1 year after birth. Data are collected by the treating physician and transferred online to a national coordinator, who reviews the reports for completeness and accuracy before transmission to the central database in Milan, Italy.

The registry was established in 1999 and has involved 42 countries with $>1,500$ collaborators (coinvestigators, links.lww. com/WNL/A946). The prevalence of MCMs associated with the 8 most common monotherapies at different dose levels has recently been reported. ${ }^{6}$ In the current analysis, we focus on changes in use of different AED treatments and in teratogenic outcomes for pregnancies where conception (based on date of last menstrual period) occurred between 2000 and 2013. Due to the need for follow-up of outcomes and data validation, the cutoff date for the present analysis was set at May 20, 2016, at which point 21,875 pregnancies had been registered.

\section{Exclusions}

We excluded from the current analysis retrospectively ascertained pregnancies, those occurring in women without epilepsy, those for which physicians failed to submit reports within preset deadlines, and those for which follow-up was not yet completed at the current census. We also excluded pregnancies where AEDs were switched or withdrawn during the first trimester, those exposed to other potentially teratogenic drugs, and those with comorbidities associated with teratogenic risks. For the analysis of teratogenic outcomes, we also excluded intrauterine deaths and abortions induced for causes other than fetal abnormalities and pregnancies in which fetal outcome could not be determined; pregnancies that resulted in offspring with genetic or chromosomal abnormalities were also excluded, as well as those with incomplete 12 months' postnatal follow-up. The selection process is summarized in figure 1.

\section{Definition of drug exposures}

Pregnancies were classified based on type and dosage of AEDs at conception. Seizures were classified as either generalized tonic-clonic (GTC) or other types, and epilepsy syndromes broadly according to International League Against Epilepsy criteria at the time EURAP was launched. ${ }^{21}$ In the EURAP protocol, the term "GTC seizures" includes GTC as well as focal to bilateral tonic-clonic seizures. Family history of MCMs refers to the proband's parents, excluding cerebral malformations causally associated with the maternal epilepsy. Folate supplementation was arbitrarily deemed appropriate if initiated at least 3 months before conception and maintained throughout the first trimester irrespective of dose, provided that it was no less than $0.4 \mathrm{mg} / \mathrm{d}$. 


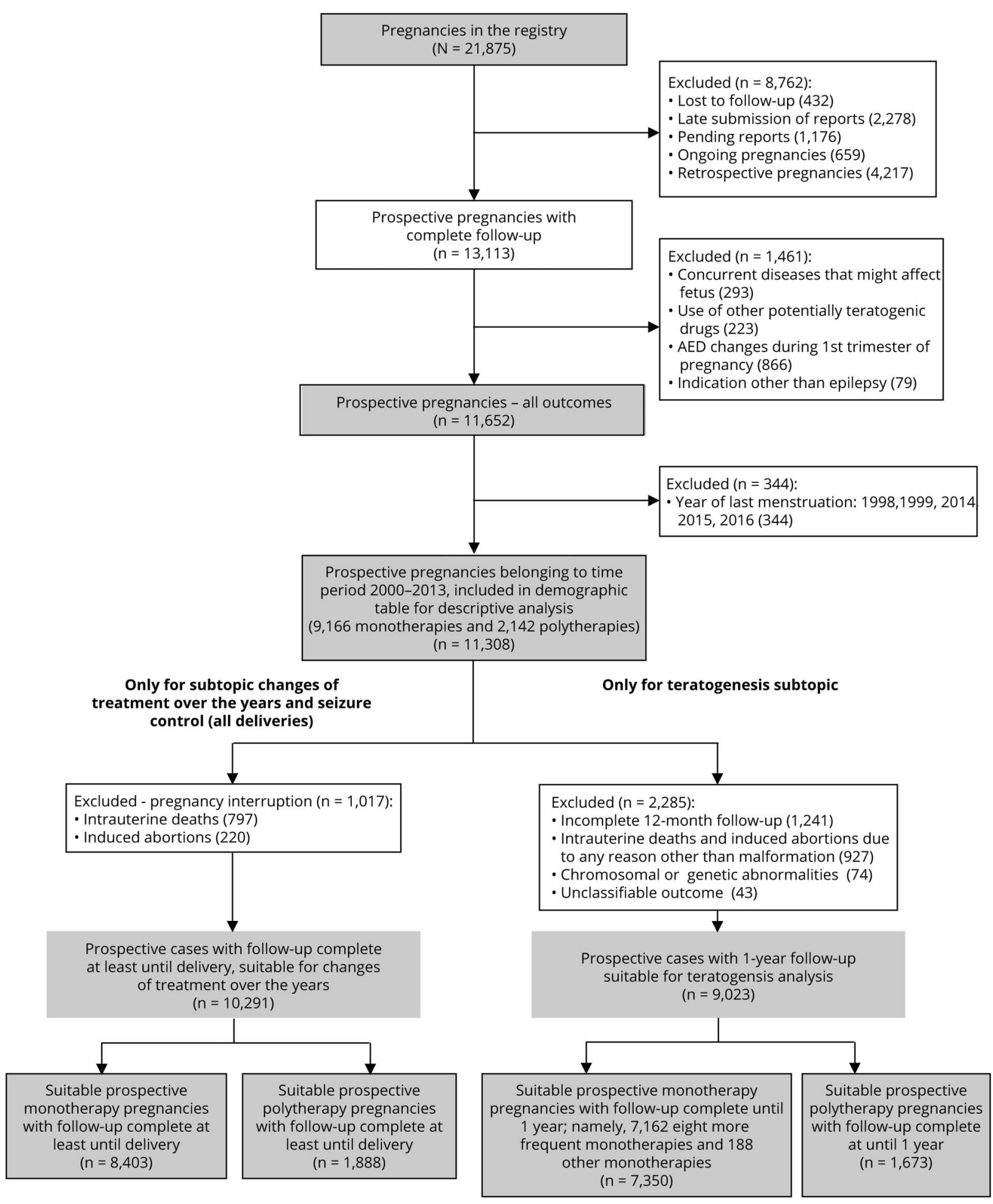

AED = antiepileptic drug.

\section{Outcomes}

Reporting physicians were instructed to report descriptively anything that they considered to be a potential abnormality in the offspring. These reports were reviewed and classified by an outcome committee unaware of the type of exposure. MCMs were defined as structural abnormalities with surgical, medical, functional, or cosmetic importance, and classified according to EUROCAT criteria 2005. ${ }^{22}$ To calculate frequencies of MCMs, the numerator was the sum of all live births plus pregnancy losses with confirmed MCMs, while the 
Table 1 Demographics and clinical details of the study cohort $(n=11,308)$

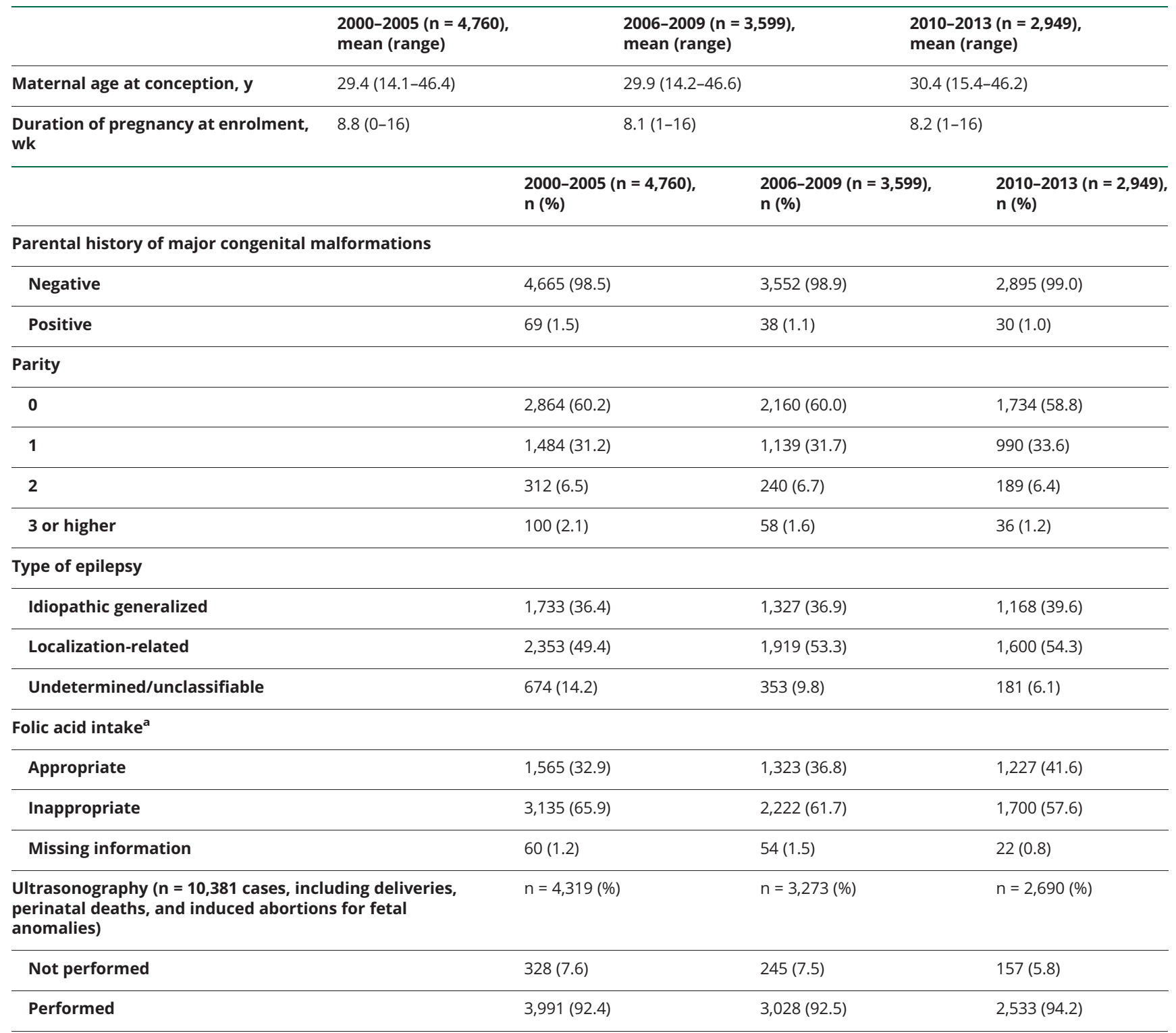

a Folate supplementation was arbitrarily deemed appropriate if started at least 3 months before conception and maintained throughout the first trimester of pregnancy at a dose of no less than $0.4 \mathrm{mg} / \mathrm{d}$.

denominator included live births, pregnancies terminated electively for MCMs, and perinatal deaths.

Information on obstetric outcomes and occurrence of GTC seizures was also obtained from reporting physicians.

\section{Statistical analysis}

To analyze time trends, pregnancies were divided into 3 groups based on the year of conception: 2000-2005, 2006-2009, and 2010-2013. The time periods were defined before the analysis to reflect hypothesized differences in treatment selection as a result of emerging data on the comparative teratogenicity of AEDs, taking also into account the need to ensure reasonable numbers of pregnancies in all 3 periods. The first period, 2000 through 2005 , was selected as reference because several important studies demonstrating increased risks with valproic acid were published in 2004-2005..$^{23-25}$ Further influential studies providing comparative data on teratogenic effects of different AEDs were published between 2009 and $2011,{ }^{5,9,26}$ justifying a split between 2006-2009 and 2010-2013 in our analysis.

The Cochrane-Armitage test, available in procedure MULTTEST of SAS software version 9.4, was used for linear trend analysis of the frequency of MCMs during the 3 time periods. This analysis was confined to pregnancies with exposure to the 8 most frequently used AEDs (in total $97.4 \%$ of all monotherapy exposures) for which the frequency of MCMs at different dose levels has been defined in a previous publication. ${ }^{6}$ As a second step, and to assess the effect of changes in AED treatment on the 
Table 2 Antiepileptic drug treatment in the study cohort $(n=11,308)$

\begin{tabular}{|c|c|c|c|}
\hline & $\begin{array}{l}2000-2005 \\
\text { n (\%) }\end{array}$ & $\begin{array}{l}\text { 2006-2009, } \\
\text { n (\%) }\end{array}$ & $\begin{array}{l}\text { 2010-2013, } \\
\text { n (\%) }\end{array}$ \\
\hline $\begin{array}{l}\text { Proportion of pregnancies exposed to monotherapy vs polytherapy during } \\
\text { the first trimester }\end{array}$ & $n=4,760$ & $n=3,599$ & $n=2,949$ \\
\hline Monotherapy & $3,825(80.4)$ & 2,934 (81.5) & 2,407 (81.6) \\
\hline Polytherapy & 935 (19.6) & 665 (18.5) & $542(18.4)$ \\
\hline Monotherapy exposures during first trimester of pregnancy $(n=9,166)$ & $n=3,825$ & $n=2,934$ & $n=2,407$ \\
\hline Lamotrigine & $994(26.0)$ & 1,086 (37.0) & $1,006(41.8)$ \\
\hline Carbamazepine & $1,259(32.9)$ & $655(22.3)$ & $419(17.4)$ \\
\hline Valproic acid & $891(23.3)$ & $541(18.4)$ & $276(11.5)$ \\
\hline Levetiracetam & $53(1.4)$ & $220(7.5)$ & 406 (16.9) \\
\hline Oxcarbazepine & $146(3.8)$ & $151(5.1)$ & $115(4.8)$ \\
\hline Phenobarbital & $207(5.4)$ & $84(2.9)$ & $64(2.7)$ \\
\hline Topiramate & $49(1.3)$ & $93(3.2)$ & $59(2.4)$ \\
\hline Phenytoin & $97(2.5)$ & $37(1.3)$ & $14(0.6)$ \\
\hline Other monotherapies & $129(3.4)$ & $67(2.3)$ & $48(2.0)$ \\
\hline Polytherapy during first trimester $(n=2,142)$ & $\mathrm{n}=935$ & $n=665$ & $n=542$ \\
\hline First trimester polytherapy with valproic acid & $335(35.8)$ & $184(27.7)$ & $119(22.0)$ \\
\hline First trimester polytherapy without valproic acid & $600(64.2)$ & $481(72.3)$ & $423(78.0)$ \\
\hline \multirow[t]{2}{*}{ Mean dose of valproic acid in monotherapy exposures, mg/d $(n=1,708)$} & $\mathrm{n}=891$ & $\mathrm{n}=541$ & $n=276$ \\
\hline & 829.8 & 802.5 & 777.9 \\
\hline \multirow[t]{2}{*}{ Mean dose of valproic acid in polytherapy exposures, $\mathrm{mg} / \mathrm{d}(\mathrm{n}=638)$} & $\mathrm{n}=335$ & $\mathrm{n}=184$ & $\mathrm{n}=119$ \\
\hline & 946.8 & $1,011.1$ & 877.7 \\
\hline \multirow[t]{2}{*}{ Mean dose of carbamazepine in monotherapy exposures, $\mathrm{mg} / \mathrm{d}(\mathrm{n}=2,333)$} & $n=1,259$ & $n=655$ & $n=419$ \\
\hline & 655.6 & 637.7 & 650.9 \\
\hline Five most common polytherapies, first trimester of pregnancy ( $n=743$ cases) & $n=299$ & $n=236$ & $n=208$ \\
\hline Lamotrigine + valproic acid & $117(39.1)$ & $70(29.6)$ & $46(22.1)$ \\
\hline Lamotrigine + levetiracetam & $32(10.7)$ & $75(31.8)$ & $85(40.9)$ \\
\hline Carbamazepine + levetiracetam & $29(9.7)$ & $50(21.2)$ & $48(23.1)$ \\
\hline Carbamazepine + lamotrigine & $73(24.4)$ & $25(10.6)$ & $15(7.2)$ \\
\hline Carbamazepine + valproic acid & $48(16.1)$ & $16(6.8)$ & $14(6.7)$ \\
\hline
\end{tabular}

prevalence of MCMs, the linear trend analysis of the frequency of MCMs was adjusted for changes in AED treatment including type of AED and dose categories ${ }^{6}$ by resorting to the stratified version of Cochrane-Armitage test. The same statistical approach was also used to analyze time trends in proportion of pregnancies associated with GTC seizures, which was a secondary outcome in the present analysis.

\section{Data availability}

Data not shown in this article will be shared by request from any qualified investigator.

\section{Standard protocol approvals, registrations, and patient consents}

The protocol was approved by ethics committees of participating centers and informed consent was obtained from all women, in writing or orally depending on the requirements in the different countries.

\section{Results}

Of the 21,875 pregnancies in the database, 11,308 prospective pregnancies (9,724 from Europe, 1,425 from Asia-Oceania, 


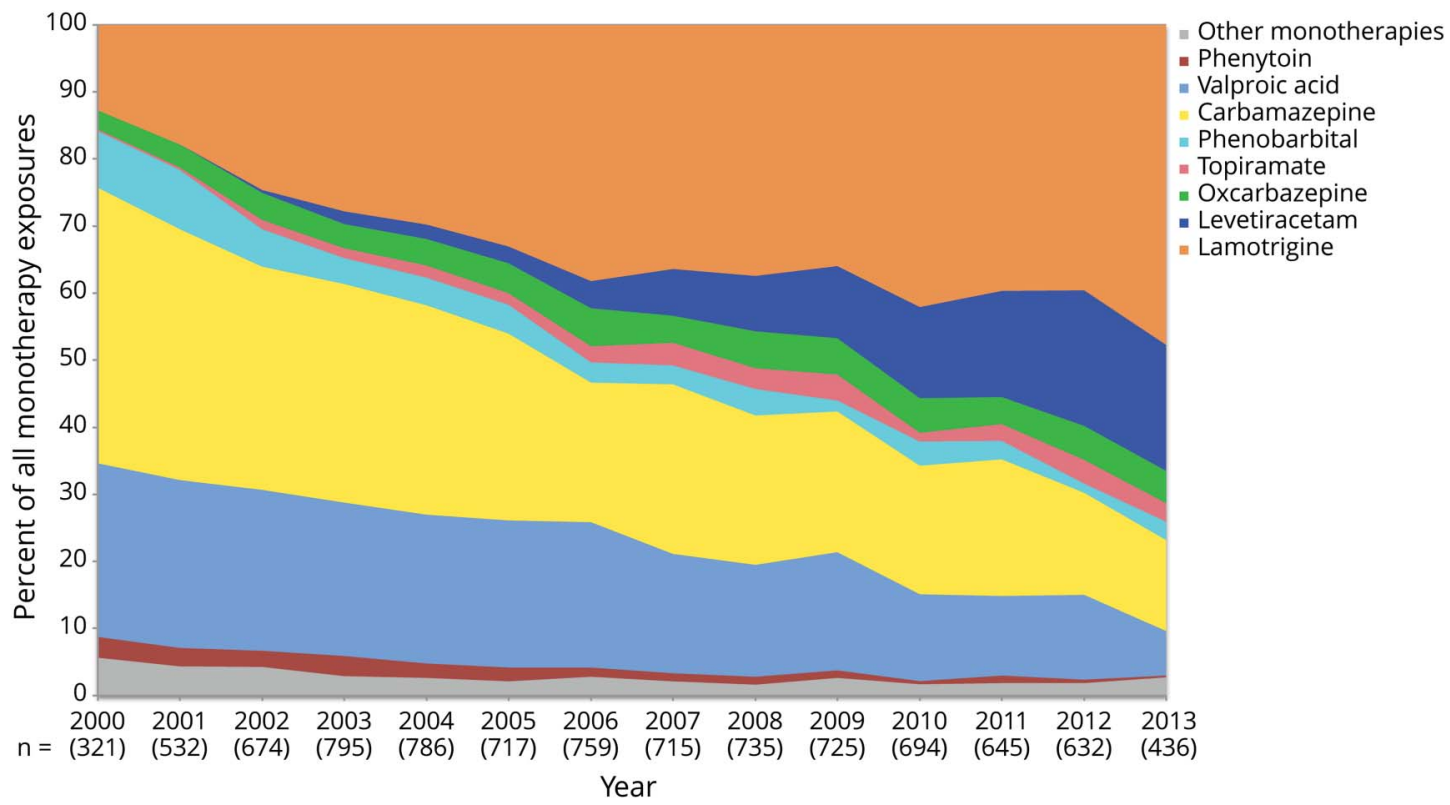

Proportion of different antiepileptic drug monotherapies (expressed as \% of all monotherapy exposures) over time in pregnancies enrolled in EURAP from 2000 through 2013.

and 159 from the Americas) were enrolled over the predefined time periods (table 1 for demographic and clinical data). Of these, 10,291 occurring in a total of 8,958 women (1,032 contributed two pregnancies, 73 three pregnancies, and 1 four or more pregnancies) met the criteria for inclusion in the analysis of treatment changes and seizure control, whereas 9,023 occurring in a total of 7,839 women (923 contributed two pregnancies, 63 three pregnancies, and 1 four or more pregnancies) met the criteria for analysis of teratogenic outcomes (figure 1). Maternal age, duration of pregnancy at enrollment, parental history of MCMs, parities, types of epilepsy, and use of prenatal ultrasound investigation were similar across the 3 time periods.

The proportion of pregnancies with appropriate folic acid supplementation increased over time, although it remained below $50 \%$ throughout the study period. The proportion of pregnancies exposed to AED monotherapy was similar across all periods (80.4\%-81.6\%), but there were major changes over time in the type of AEDs used in monotherapy (table 2). In particular, there was a progressive decline in the use of valproic acid and carbamazepine, and an increase in the use of lamotrigine and levetiracetam (figure 2). The use of valproic acid in combination therapy also decreased markedly from the first to the second and to the third time periods (table 2).

Teratogenic outcomes and seizure control data during the 3 time periods are summarized in table 3 . The prevalence of MCMs after monotherapy exposure decreased from $6.0 \%$ during 2000-2005 to 4.4\% during 2010-2013. Corresponding figures for polytherapy exposure were $8.3 \%$ and $6.1 \%$, respectively. The change over time in frequency of MCMs after monotherapy exposure showed a significant negative linear trend in the crude analysis $(p=0.0087)$, which was no longer present after adjustment for changes in AED treatment $(p=0.9923)$.

Figure 3 shows data for 8 broad categories of MCMs detected over the 3 time periods after monotherapy and polytherapy exposure. Compared with the first time period, the prevalence of MCMs decreased for most categories except for renal malformations and for multiple MCMs.

There were no significant changes over time in the proportion of pregnancies associated with GTC seizures $(p=0.1210)$ (table 3).

\section{Discussion}

The present study demonstrates a significant trend for the prevalence of MCMs to decrease during the 14-year period that preceded the strengthening of EMA restrictions on the use of valproic acid. After adjustment for changes in AED treatment, this trend was no longer present, suggesting that the improved teratogenic outcomes were causally related to the changes in type of AED exposure. During the study period, the use of valproic acid monotherapy decreased markedly from $25.9 \%$ of all monotherapies in 2000 to $6.7 \%$ in 2013 , and that of carbamazepine from $41.1 \%$ to $13.5 \%$ (figure 2 ). The use of valproic acid in polytherapy regimens also declined markedly during the same period, whereas the use of lamotrigine and levetiracetam increased considerably (table 2). Since valproic acid is associated with a much higher risk for 
Table 3 Seizure control and prevalence of major congenital malformations during 3 time periods $(n=11,308$ all cases, 10,291 deliveries)

\begin{tabular}{|c|c|c|c|}
\hline & $\begin{array}{l}2000-2005 \\
\text { n (\%) }\end{array}$ & $\begin{array}{l}2006-2009 \\
\text { n (\%) }\end{array}$ & $\begin{array}{l}2010-2013 \\
\text { n (\%) }\end{array}$ \\
\hline Obstetric outcome ( $n=11,308$ all cases) & $n=4,760$ & $n=3,599$ & $\mathrm{n}=2,949$ \\
\hline Delivered & $4,284(90.0)$ & $3,270(90.9)$ & $2,682(91.0)$ \\
\hline Induced abortions, intrauterine deaths, and perinatal deaths & $476(10.0)$ & $329(9.1)$ & $267(9.0)$ \\
\hline Generalized tonic-clonic seizures during pregnancy ( $n=10,291$ deliveries) & $n=4,272$ & $\mathrm{n}=3,254$ & $\mathrm{n}=2,675$ \\
\hline Yes & $833(19.5)$ & $636(19.5)$ & $460(17.2)$ \\
\hline No (either seizure-free or other seizure types) & $3,439(80.5)$ & $2,618(80.5)$ & $2,215(82.8)$ \\
\hline Status epilepticus during pregnancy $(n=10,291$ deliveries) & $n=4,275$ & $\mathrm{n}=3,250$ & $\mathrm{n}=2,677$ \\
\hline Convulsive status epilepticus & $18(0.4)$ & $9(0.3)$ & $6(0.2)$ \\
\hline Nonconvulsive status epilepticus & $20(0.5)$ & $11(0.3)$ & $3(0.1)$ \\
\hline No status epilepticus & $4,237(99.1)$ & $3,230(99.4)$ & $2,668(99.7)$ \\
\hline Teratogenic outcomes, monotherapy ( $n=7,162 ; 8$ most common AEDs) & $\mathrm{n}=2,984$ & $n=2,246$ & $\mathrm{n}=1,932$ \\
\hline Major congenital malformations & $180(6.0)$ & $108(4.8)$ & $85(4.4)$ \\
\hline No major congenital malformations & $2,804(94.0)$ & $2,138(95.2)$ & $1,847(95.6)$ \\
\hline Teratogenic outcomes, all monotherapy cases $(n=7,350)$ & $n=3,087$ & $\mathrm{n}=2,294$ & $\mathrm{n}=1,969$ \\
\hline Major congenital malformations & $181(5.9)$ & $109(4.8)$ & $86(4.4)$ \\
\hline No major congenital malformations & $2,906(94.1)$ & $2,185(95.2)$ & $1,883(95.6)$ \\
\hline Teratogenic outcomes, polytherapy $(n=1,673)$ & $n=736$ & $n=508$ & $n=429$ \\
\hline Major congenital malformations & $61(8.3)$ & $35(6.9)$ & $26(6.1)$ \\
\hline No major congenital malformations & $675(91.7)$ & $473(93.1)$ & $403(93.9)$ \\
\hline
\end{tabular}

Abbreviation: $A E D=$ antiepileptic drug.

MCMs than lamotrigine and levetiracetam, ${ }^{2,3,6,27}$ it is reasonable to assume that the decrease in occurrence of MCMs is explained mainly by the pronounced decline in exposure to valproic acid. This assumption is further supported by the fact that the prevalence of types of MCMs found to be associated with valproic acid exposure in previous studies, such as hypospadias, neural tube defects, and polydactyly, ${ }^{6,28-31}$ also decreased over time (figure 3). Other changes in type of AED may also have contributed to the improved teratogenic outcomes. In particular, carbamazepine and phenobarbital, the use of which declined during the study period, have been associated with higher risks of MCMs compared with levetiracetam and lamotrigine. , $3,6,27^{-}$

The risk of MCMs with several AEDs, including valproic acid and carbamazepine, has been shown to be dose-dependent. ${ }^{2,3,6,7}$ However, changes over time in the doses of valproic acid and carbamazepine (table 2) were not of a magnitude that is likely to explain the improved teratogenic outcomes. In addition, there were no major changes over time in the prevalence of MCMs with the 3 most frequently used AEDs-lamotrigine, carbamazepine, or valproic acid (data not shown) - supporting the interpretation that the decrease in overall prevalence of MCMs is a result of changes in drug selection rather than a time effect. Although there was an increase over time in the use of appropriate folate supplementation (table 1), a recent analysis of data from the EURAP cohort did not identify a protective effect of folate against the risk of MCMs associated with AED exposure. ${ }^{6}$ Therefore, it is unlikely that greater use of folic acid had a major role in the reduction in teratogenic outcomes shown by the current analysis.

A challenge in managing epilepsy during pregnancy is to balance the teratogenic risks of treatment against the fetal and maternal risks associated with poorly controlled seizures. ${ }^{30,32}$ It is therefore reassuring that there was no indication of deterioration in control of GTC seizures or in the occurrence of status epilepticus over time in parallel with changes in prescribing patterns, and, in particular, with the increased use of lamotrigine and levetiracetam at the expense of valproic acid and carbamazepine (table 3). This is somewhat surprising because earlier EURAP findings had suggested poorer control of GTC seizures during pregnancy with lamotrigine compared with valproic acid use. ${ }^{33}$ Possibly, unchanged seizure 


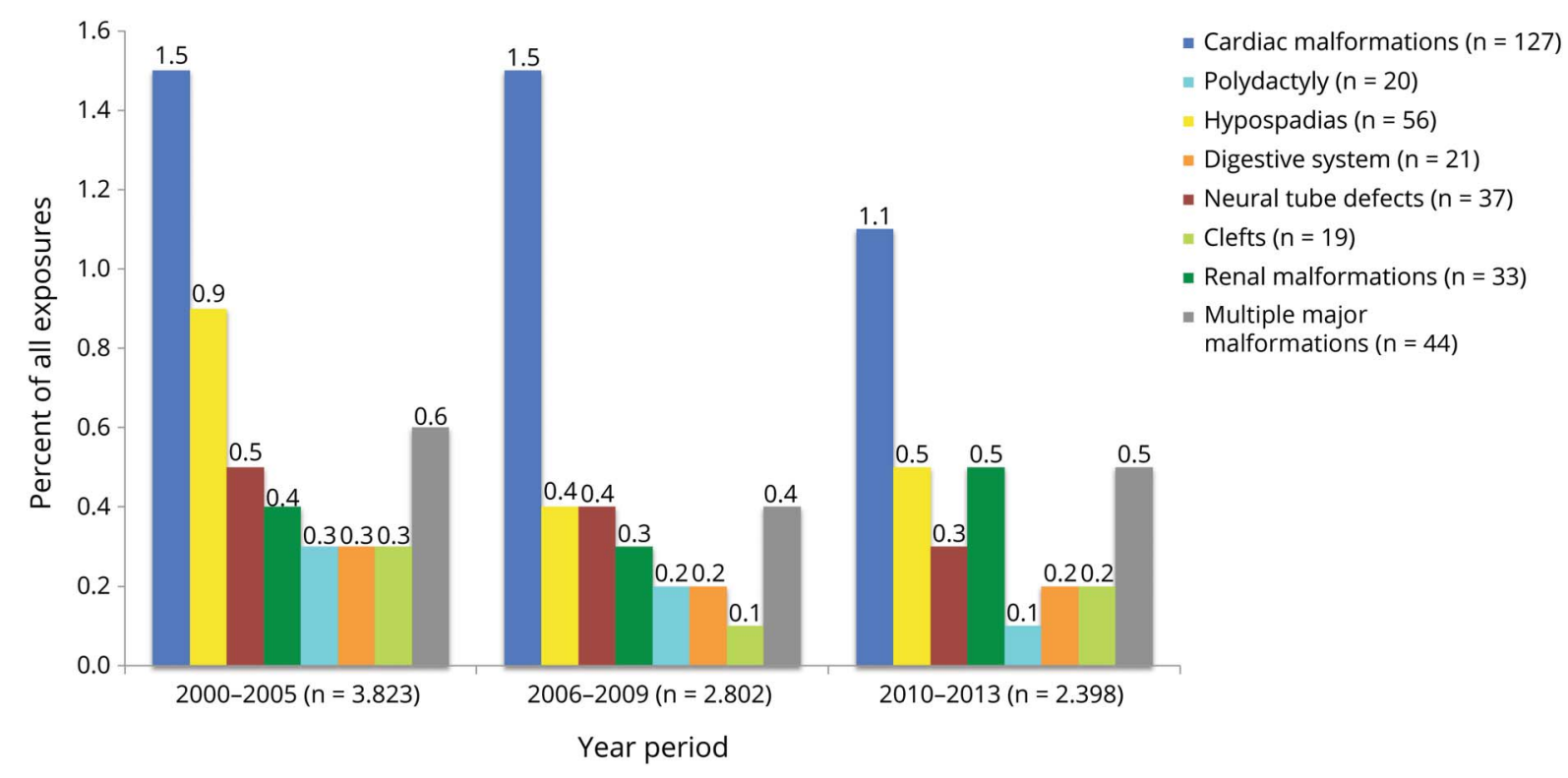

Prevalence of different categories of major congenital malformations (expressed as \% of all exposures) in offspring exposed prenatally to antiepileptic drugs in monotherapy or polytherapy during the 3 study periods.

outcomes despite greater use of lamotrigine could be explained by increased awareness of the need for serum drug level monitoring and dose adjustments during pregnancy ${ }^{34}$ and also by more careful individualization of AED selection where valproic acid may have been reserved for the more difficult to treat. It should be acknowledged that there are individual cases in whom valproic acid is the most and sometimes the only effective treatment, particularly in generalized epilepsies. $^{32}$

Other authors have reported changes in AED utilization over time in young women ${ }^{15,16}$ or during pregnancy, ${ }^{18}$ generally showing a decrease in the use of valproic acid. The Australian Register of AEDs in Pregnancy, which contributes pregnancies to EURAP (5.5\% of the current cohort), compared data on 855 pregnancies enrolled in 1995-2005 with 801 pregnancies enrolled in 2006-2012 and found a significant decrease in the use of carbamazepine and valproic acid, albeit smaller than in our cohort, but no decrease in frequency of MCMs. ${ }^{19} \mathrm{~A}$ more recent report from the United Kingdom and Ireland pregnancy register also found a decrease in the use of valproic acid and carbamazepine and an increase in the use of lamotrigine and levetiracetam between 1996 and 2016, which was associated with a small, not significant annual reduction in MCM rate. ${ }^{17}$

Our study has a number of limitations. First, the EURAP cohort is not population-based and most of the enrolled patients are managed by physicians with a special interest in the management of epilepsy in women of childbearing potential. Therefore, the observed trends in prescribing patterns may not be representative of trends in women with epilepsy at large. However, this does not invalidate the important observation that the reported treatment changes were associated with a reduced frequency of MCMs. Our analysis covers 14 years of enrolment, from 2000 to 2013 . Hence, it does not assess the effect of EMA's tightened restrictions on the use of valproic acid in 2014 (EMA), but it rather reflects adjustments in prescribing patterns based on emerging data on the teratogenic potential of individual AEDs. In fact, our selection of the 3 time periods took into account time-dependent advances in level of evidence for teratogenic risks. Admittedly, a comparison between outcomes in the 3 time periods is also a comparison of different populations. However, apart from differences in AED treatment, demographic and clinical data were very similar across the treatment periods, supporting the interpretation that the observed differences in teratogenic outcomes are at least in part the result of changes in treatment patterns.

Data from this large international prospective registry documented major changes in treatment patterns in women with epilepsy during pregnancy over a 14-year period, with decreased use of valproic acid and carbamazepine and increased use of lamotrigine and levetiracetam. These changes were associated with a reduction by approximately $27 \%$ in the prevalence of MCMs, without any indication of deterioration in overall control of GTC seizures. Considering the number of women with epilepsy worldwide who become pregnant while on treatment, this improvement in outcome has major public health implications. Given that the current analysis was limited to the 8 most frequently used AEDs and MCMs as primary outcome, additional research including continued activity of the existing pregnancy registries is needed to assess the full spectrum of potential adverse outcomes, including cognitive and behavioral outcomes, after prenatal exposure to AEDs. 


\section{Study funding}

EURAP has received financial support from the following pharmaceutical companies: Bial, Eisai, GlaxoSmithKline, Janssen-Cilag, Novartis, Pfizer, Sanofi-Aventis, and UCB, from Netherlands Epilepsy Foundation (NEF) grant 03-18 (Lindhout), and from Stockholm County Council, ALF (Tomson). The sponsors had no influence on the conduct of the study, analysis, interpretation, writing of the manuscript, or the decision to publish the results.

\section{Disclosure}

T. Tomson is an employee of Karolinska Institutet, is associate editor of Epileptic Disorders, has received speaker's honoraria to his institution from Eisai, Sanofi, Sun Pharma, UCB, and Sandoz, and received research support from Stockholm County Council, EU, CURE, GSK, UCB, Eisai, and Bial. D. Battino reports no disclosures relevant to the manuscript. E. Bonizzoni has received consultancy fees from Italfarmaco, Zambon, Roche, and Helsinn. J. Craig received research grants and speaker's fees from UCB Pharma, Eisai, GSK, Sanofi-Aventis, Pfizer, and JanssenCilag. D. Lindhout received research grants from JanssenCilag, GSK, Pfizer, and Netherlands Epilepsy Foundation. A. Sabers received consultancy or lecture fees from Eisai Denmark and UCB Nordic. E. Perucca received research funds from the Italian Ministry of Health and the Italian Ministry for Education and University. He also received speaker's or consultancy fees and/or research grants from Axovant, Eisai, Sanofi, Takeda, UCB Pharma, and Xenon Pharma and has been on advisory boards of Biogen, Eisai, and GW Pharma. S. Thomas has received speakers' honoraria from the BMJ India and royalties from John Wiley for his monogram on epilepsy in women. F. Vajda reports no disclosures relevant to the manuscript. Go to Neurology. org/ $\mathrm{N}$ for full disclosures.

\section{Publication history}

Received by Neurology December 20, 2018. Accepted in final form April 1, 2019.

\section{Appendix 1 Authors}

\begin{tabular}{llll}
\hline Name & Location & Role & Contribution \\
\hline $\begin{array}{l}\text { Torbjorn } \\
\text { Tomson, } \\
\text { MD }\end{array}$ & $\begin{array}{l}\text { Department of Clinical } \\
\text { Neuroscience, } \\
\text { Karolinska Institutet; } \\
\text { Department of } \\
\text { Neurology, Karolinska }\end{array}$ & $\begin{array}{l}\text { Author } \\
\text { Cesigned and } \\
\text { conceptualized study, } \\
\text { drafted the } \\
\text { manuscript for } \\
\text { intellectual content }\end{array}$ \\
& Stockholm, Sweden & \\
\hline Dina & Epilepsy Center, & Author & Designed and \\
Battino, & Department of & & conceptualized study, \\
MD & Neurophysiology and & & $\begin{array}{l}\text { drafted the } \\
\text { manuscript for } \\
\text { intellectual content }\end{array}$ \\
& Experimental & \\
& Epileptology, & & \\
& Fondazione IRCCS & & \\
& Istituto Neurologico & & \\
& Carlo Besta, Milan, Italy & & \\
\hline
\end{tabular}

Appendix 1 (continued)

\begin{tabular}{|c|c|c|c|}
\hline Name & Location & Role & Contribution \\
\hline $\begin{array}{l}\text { Erminio } \\
\text { Bonizzoni, } \\
\text { PhD }\end{array}$ & $\begin{array}{l}\text { Department of Clinical } \\
\text { Science and } \\
\text { Community, Section of } \\
\text { Medical Statistics and } \\
\text { Biometry "G.A. } \\
\text { Maccacaro," Faculty of } \\
\text { Medicine and Surgery, } \\
\text { University of Milan, Italy }\end{array}$ & Author & $\begin{array}{l}\text { Designed and } \\
\text { conceptualized study, } \\
\text { performed statistical } \\
\text { analysis, revised the } \\
\text { manuscript for } \\
\text { intellectual content }\end{array}$ \\
\hline $\begin{array}{l}\text { John Craig, } \\
\text { MD }\end{array}$ & $\begin{array}{l}\text { Belfast Health and } \\
\text { Social Care Trust, } \\
\text { Grosvenor Road, } \\
\text { Belfast, UK }\end{array}$ & Author & $\begin{array}{l}\text { Designed and } \\
\text { conceptualized study, } \\
\text { interpreted the data, } \\
\text { revised the } \\
\text { manuscript for } \\
\text { intellectual content }\end{array}$ \\
\hline $\begin{array}{l}\text { Dick } \\
\text { Lindhout, } \\
\text { MD }\end{array}$ & $\begin{array}{l}\text { Department of } \\
\text { Genetics, University } \\
\text { Medical Center } \\
\text { Utrecht; } \\
\text { Stichting Epilepsie } \\
\text { Instellingen } \\
\text { Nederland (SEIN), } \\
\text { Heemstede, the } \\
\text { Netherlands }\end{array}$ & Author & $\begin{array}{l}\text { Designed and } \\
\text { conceptualized study, } \\
\text { interpreted the data, } \\
\text { revised the } \\
\text { manuscript for } \\
\text { intellectual content }\end{array}$ \\
\hline $\begin{array}{l}\text { Emilio } \\
\text { Perucca, } \\
\text { MD }\end{array}$ & $\begin{array}{l}\text { Department of } \\
\text { Internal Medicine and } \\
\text { Therapeutics, } \\
\text { University of Pavia; } \\
\text { Clinical Trial Center, } \\
\text { IRCCS Mondino } \\
\text { Foundation, Pavia, } \\
\text { Italy }\end{array}$ & Author & $\begin{array}{l}\text { Designed and } \\
\text { conceptualized study, } \\
\text { interpreted the data, } \\
\text { revised the } \\
\text { manuscript for } \\
\text { intellectual content }\end{array}$ \\
\hline $\begin{array}{l}\text { Anne } \\
\text { Sabers, } \\
\text { MD }\end{array}$ & $\begin{array}{l}\text { The Epilepsy Clinic, } \\
\text { Department of } \\
\text { Neurology, } \\
\text { Rigshospitalet- } \\
\text { Blegdamsvej, } \\
\text { University State } \\
\text { Hospital, Copenhagen, } \\
\text { Denmark }\end{array}$ & Author & $\begin{array}{l}\text { Designed and } \\
\text { conceptualized study, } \\
\text { interpreted the data, } \\
\text { revised the } \\
\text { manuscript for } \\
\text { intellectual content }\end{array}$ \\
\hline $\begin{array}{l}\text { Sanjeev V. } \\
\text { Thomas, } \\
\text { MD }\end{array}$ & $\begin{array}{l}\text { Department of } \\
\text { Neurology, Sree Chitra } \\
\text { Tirunal Institute of } \\
\text { Medical Sciences and } \\
\text { Technology, } \\
\text { Trivandrum, Kerala } \\
\text { State, India }\end{array}$ & Author & $\begin{array}{l}\text { Designed and } \\
\text { conceptualized study, } \\
\text { interpreted the data, } \\
\text { revised the } \\
\text { manuscript for } \\
\text { intellectual content }\end{array}$ \\
\hline $\begin{array}{l}\text { Frank } \\
\text { Vajda, MD }\end{array}$ & $\begin{array}{l}\text { Departments of } \\
\text { Medicine and } \\
\text { Neurology, University } \\
\text { of Melbourne; } \\
\text { Monash University; } \\
\text { Royal Melbourne } \\
\text { Hospital, Australia }\end{array}$ & Author & $\begin{array}{l}\text { Designed and } \\
\text { conceptualized study, } \\
\text { interpreted the data, } \\
\text { revised the } \\
\text { manuscript for } \\
\text { intellectual content }\end{array}$ \\
\hline
\end{tabular}

\section{Appendix 2 Coinvestigators}

Coinvestigators are listed at links.Iww.com/WNL/A946

\section{References \\ 1. Meadow SR. Anticonvulsant drugs and congenital abnormalities. Lancet 1968;2: 1296. \\ 2. Campbell E, Kennedy F, Russell A, et al. Malformation risks of antiepileptic drug monotherapies in pregnancy: updated results from the UK and Ireland Epilepsy and Pregnancy Registers. J Neurol Neurosurg Psychiatry 2014;85:1029-1034. \\ 3. Hernandez-Diaz S, Smith CR, Shen A, et al. Comparative safety of antiepileptic drugs during pregnancy. Neurology 2012;78:1692-1699.}


4. Thomas SV, Jose M, Divakaran S, Sankara Sarma P. Malformation risk of antiepileptic drug exposure during pregnancy in women with epilepsy: results from a pregnancy registry in South India. Epilepsia 2017;58:274-281.

5. Tomson T, Battino D, Bonizzoni E, et al. Dose-dependent risk of malformations with antiepileptic drugs: an analysis of data from the EURAP epilepsy and pregnancy registry. Lancet Neurol 2011;10:609-617.

6. Tomson T, Battino D, Bonizzoni E, et al. Comparative risk of major congenital malformations with eight different antiepileptic drugs: a prospective cohort study of the EURAP registry. Lancet Neurol 2018;17:530-538.

7. Vajda FJ, O’Brien TJ, Graham JE, Lander CM, Eadie MJ. Dose dependence of fetal malformations associated with valproate. Neurology 2013;81:999-1003.

8. Baker GA, Bromley RL, Briggs M, et al. IQ at 6 years after in utero exposure to antiepileptic drugs: a controlled cohort study. Neurology 2015;84:382-390.

9. Meador KJ, Baker GA, Browning N, et al. Cognitive function at 3 years of age after fetal exposure to antiepileptic drugs. N Engl J Med 2009;360:1597-1605.

10. Meador KJ, Baker GA, Browning N, et al. Fetal antiepileptic drug exposure and cognitive outcomes at age 6 years (NEAD study): a prospective observational study. Lancet Neurol 2013;12:244-252.

11. Christensen J, Gronborg TK, Sorensen MJ, et al. Prenatal valproate exposure and risk of autism spectrum disorders and childhood autism. JAMA 2013;309: 1696-1703.

12. Omtzigt JG, Nau H, Los FJ, Pijpers L, Lindhout D. The disposition of valproate and its metabolites in the late first trimester and early second trimester of pregnancy in maternal serum, urine, and amniotic fluid: effect of dose, co-medication, and the presence of spina bifida. Eur J Clin Pharmacol 1992;43:381-388.

13. FDA Drug Safety Communication. Valproate anti-seizure products contraindicated for migraine prevention in pregnant women due to decreased IQ scores in exposed children (issued June 5, 2013). Available at: fda.gov/Drugs/DrugSafety/ucm350684. htm. Accessed September 12, 2017.

14. European Medicines Agency. Assessment report: procedure under Article 31 of Directive 2001/83/EC resulting from pharmacovigilance data. Available at: ema.europa. eu/docs/en_GB/document_library/Referrals_document/Valproate_and_related substances 31/Recommendation_provided by_Pharmacovigilance_Risk_Assessment_Committee/WC500177352.pdf. Accessed April 10, 2018.

15. Karlsson Lind L, Komen J, Wettermark B, von Euler M, Tomson T. Valproic acid utilization among girls and women in Stockholm: impact of regulatory restrictions. Epilepsia Open 2018;3:357-363.

16. Virta LJ, Kalviainen R, Villikka K, Keranen T. Declining trend in valproate use in Finland among females of childbearing age in 2012-2016: a nationwide registry-based outpatient study. Eur J Neurol 2018;25:869-874.

17. Kinney MO, Morrow J, Patterson CC, et al. Changing antiepilepsy drugprescribing trends in women with epilepsy in the UK and Ireland and the impact on major congenital malformations. J Neurol Neurosurg Psychiatry 2018;89: 1320-1323.

18. Meador KJ, Pennell PB, May RC, et al. Changes in antiepileptic drug-prescribing patterns in pregnant women with epilepsy. Epilepsy Behav 2018;84:10-14.

19. Vajda FJ, O’Brien TJ, Graham J, Lander CM, Eadie MJ. The Australian Register of antiepileptic drugs in pregnancy: changes over time in the epileptic population. J Clin Neurosci 2014;21:1478-1482.

20. Lindhout D, Meinardi H, Meijer JW, Nau H. Antiepileptic drugs and teratogenesis in two consecutive cohorts: changes in prescription policy paralleled by changes in pattern of malformations. Neurology 1992;42:94-110.

21. Commission on Classification and Terminology of the International League against Epilepsy. Proposal for revised classification of epilepsies and epileptic syndromes.Epilepsia 1989;30:389-399.

22. EUROCAT Guide 1.3: Instructions for the Registration of Congenital Anomalies: EUROCAT Central Registry. Belfast: University of Ulster; 2005.

23. Adab N, Kini U, Vinten J, et al. The longer term outcome of children born to mothers with epilepsy. J Neurol Neurosurg Psychiatry 2004;75:1575-1583.

24. Vinten J, Adab N, Kini U, Gorry J, Gregg J, Baker GA. Neuropsychological effects of exposure to anticonvulsant medication in utero. Neurology 2005;64:949-954.

25. Wyszynski DF, Nambisan M, Surve T, Alsdorf RM, Smith CR, Holmes LB. Increased rate of major malformations in offspring exposed to valproate during pregnancy. Neurology 2005;64:961-965.

26. Bromley RL, Mawer G, Love J, et al. Early cognitive development in children born to women with epilepsy: a prospective report. Epilepsia 2010;51:2058-2065.

27. Veroniki AA, Cogo E, Rios P, et al. Comparative safety of anti-epileptic drugs during pregnancy: a systematic review and network meta-analysis of congenital malformations and prenatal outcomes. BMC Med 2017;15:95.

28. Clayton-Smith J, Donnai D. Fetal valproate syndrome. J Med Genet 1995;32:724-727.

29. Jentink J, Loane MA, Dolk H, et al. Valproic acid monotherapy in pregnancy and major congenital malformations. N Engl J Med 2010;362:2185-2193.

30. Tomson T, Battino D. Teratogenic effects of antiepileptic drugs. Lancet Neurol 2012; 11:803-813.

31. Tomson T, Battino D, Perucca E. Valproic acid after five decades of use in epilepsy: time to reconsider the indications of a time-honoured drug. Lancet Neurol 2016;15:210-218.

32. Tomson T, Marson A, Boon P, et al. Valproate in the treatment of epilepsy in girls and women of childbearing potential. Epilepsia 2015;56:1006-1019.

33. Battino D, Tomson T, Bonizzoni E, et al. Seizure control and treatment changes in pregnancy: observations from the EURAP epilepsy pregnancy registry. Epilepsia 2013;54:1621-1627.

34. Tomson T, Johannessen Landmark C, Battino D. Antiepileptic drug treatment in pregnancy: changes in drug disposition and their clinical implications. Epilepsia 2013, $54: 405-414$. 